\title{
A Research on the Sustainable Development of Foreign Language Talents in China's West Region under the Background of "The Belt and Road Construction"
}

\author{
Juan Lu
}

School of Foreign Studies, Shaanxi University of Technology, Hanzhong, Shaanxi, China, 723000

672241343@qq.com

\begin{abstract}
Because of the high unemployment rate, English Major in China's West region has been listed as red card warning major for several years by the Max employment report, facing the threat of being canceled. The Belt and Road construction policy has brought a new dawn for foreign language talents in Western Region because the construction of the Silk Road stretches across three continents: Asia, Europe and Africa, which will provide huge employment market for foreign language talents. However, The Belt and Road construction no longer needs the traditional pure language talents while urgently needs Inter-disciplinary foreign language talents. Therefore, foreign language talents in Western Region must develop themselves into "Interdisciplinary research type, Interdisciplinary major type, Interdisciplinary language type, Interdisciplinary technology type and Interdisciplinary management type", and then they can achieve a sustainable development.
\end{abstract}

Keywords: "The belt and road construction"; China's west region; Sustainable development; Inter-disciplinary foreign language talents

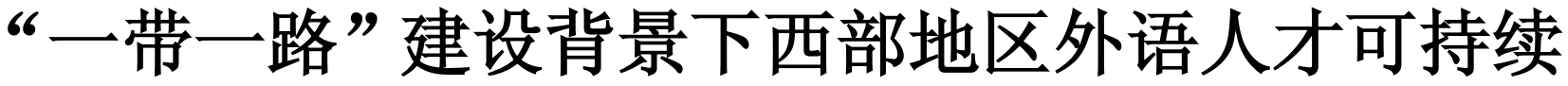

\section{发展}

陆娟

陕西理工大学 外国语学院, 陕西 汉中 723000 .

摘要: 由于失业率高, 我国西部地区的英语专业连续数年为麦克斯就业报告中的红牌专业, 面临被取缔的威胁。“一带 一路”建设国策的提出为西部地区外语人才带来了新的曙光, 因为丝路建设跨越亚、非、欧三洲, 将为外语人才提供巨大的 就业市场。然而, “一带一路” 建设不再需要传统的纯语言型外语人才, 而迫切需求复合型外语人才。因此。西部地区的外 语人才必须向 “复合研究型、复合专业型、复合语种型、复合技术型、复合管理型”方向发展，才有可持续发展的出路。

关键词: “一带一路”建设、西部地区、可持续发展、复合型外语人才

\section{引言}

党的十八届三中全会强调，要 “加快同周边国家和区域基础设施互联互通建设，推进“新丝绸之路经 济带”、“21 世纪海上丝绸之路” 建设, 形成全方位开放新格局”。2014 年 11 月 8 日, 习总书记宣布, 中 国将出资 400 亿美元成立丝路基金，为 “一带一路” 沿线国家基础设施建设、资源开发、产业合作等有关 项目提供投融资支持。“一带一路” 建设跨越亚、欧、非三洲, 造福全球 44 亿人口, 将带来世界上最大的 欧亚大陆一体化及其全面复兴。这是 “中国梦”、“亚太梦”，更是 “世界梦”、“人类梦”，而实现这一世界 梦的先决条件是为 “一带一路” 建设培养外语人才。语言和道路不通是 “一带一路” 建设的主要障碍, 国 家政府在规划施工中巴铁路, 中尼铁路、中吉乌铁路的同时, 西部各省已经开始为丝路建设制定 “以人为 本” 的外语人才规划方案。合格外语人才贯乏是 “一带一路” 建设进程中的重大难题, “一带一路” 建设 的实施和实现主要取决于外语人才的交流、翻译与宣传能力 ${ }^{[1]}$ 。 


\section{1 西部地区外语人才发展现状}

近年来, 我国西部地区外语专业人才由于失业率高、社会适应性差、职场成就低等原因, 成了 “无专 业特色, 无技能特点, 无岗位特质” 的 “三无” 人员。他们由于专业缺失不能满足社会需求和职场需要, 一方面是企业苦于招聘不到 “招进来就能胜任” 的外语人才; 另一方面, 英语专业毕业生的失业人数高居 本科热门专业失业榜第三位 ${ }^{[2]}$ 。西部地区外语类人力资源开发长期处于落后水平, 已经成为西部大开发的 掣肘环节, 也是 “一带一路” 建设进程中的主要障碍。总结起来西部地区外语人才结构主要存在以下问题: 第一, 过于偏向英语语种, 造成其他小语种虽面临较大需求, 但人才供给却跟不上的困境; 第二, 西部地 区的语言教育政策和体系是自上而下，开设科目来自于行政规划而不是市场、民间需求，造成：很多公司 和企业急需具有某项专业技能的英语人才, 而大量的外语人才找不到专业对口的工作，长期处于失业或转 业的局面。第三, 西部地区贫穷偏远山区的外语人才质量远远赶不上经济较发达城市, 由于信息闭塞, 资 源落后, 他们在学校学到的内容与实际生活和职场需求严重脱节; 第四, 我国西部地区的少数名族较多, 西部的一些少数民族地区实施民族语言和汉语 “双语教育”, 同时还要教授英语, 而大多数少数民族地区 均无法实现这一方针的师资配备, 外语人才质量自然不高; 第五, 基础外语人才培养与大学外语人才培养 没有形成自下而上系统化衔接的一条龙人才培养体制, 无论是基础外语人才培养还是高等外语人才培养都 只停留在语言层面上的传授, 内容重复、单一, 语言没有与实际专业结合起来, 也没有在社会上形成相应 的语言应用配套和氛围, 以致外语人才出了校门没多久就忘记所学, 这可以解释为何中国几亿人学习英语, 外国人在街头却难以找到可沟通的中国人这一奇特现象。

由于西部地区外语人才发展所存在的以上诸多问题, 造成了西部地区外语人才就业的以下局面: 第一, 西部地区外语专业失业率较高, 从 2006 年以后, 英语专业连续数年为麦克斯就业报告中的红牌专业, 面 临被取缔的威胁。第二, 由于专业缺失, 外语专业人才主要在学校和外语培训机构从事外语教育工作, 还 有一部分英语专业毕业生从事着与英语毫不相关的工作。第三, 由于缺少思辨能力、管理能力、创新能力, 外语专业人才的社会适应性差, 薪资较低, 职场成就低。事实说明西部地区的外语人才结构已经和社会经 济产业发展严重脱节。人才培养最终应服务于社会, 服务于经济建设, 而经济与社会发展需要的是既有某 一专业领域的精深知识又有良好外语表达能力的人才, 而不是单纯的纯语言型人才 ${ }^{[3]}$ 。

生产力及经济的发展以具有科学技术的人才为前提和条件，“一带一路”建设更应 “以人为本”，而 外语人才的开发是本中之本。受地理位置、自然环境相对落后等因素的影响和制约, 我国西部地区外语人 才发展与全国相比发展速度缓慢, 整体水平不高, 滞后于北上广、东南沿海和长江中下游地区。外语类人 力资源开发长期处于落后水平, 已经成为西部大开发的掣肘环节。在西部大开发和丝路建设的关键时期, 作为丝绸之路的重要通道, 西部地区的对外开放和资源开发的关键在于外语人才。西部地区外语人才承担 着适应区域经济社会发展需要, 服务经济发展方式转变和现代产业体系建设的时代责任, 它在缩小东西部 差距、全面建成小康社会、构建欧亚丝绸之路经济带的历史进程中发挥着不可替代的作用。只有储备数量 充足、结构合理的高质量外语人才, 才能把西部地区打造成为新丝绸之路的文化中心、旅游中心、物流中 心、商贸中心和金融中心，从而促进西部大开发的进程，促进“一带一路”建设。

\section{2 “一带一路” 建设迫切需求大量具有专业技术的外语人才}

“一带一路” 建设国策的提出为外语人才带来了新的契机。丝路建设即是升级版的西部大开发, 也是 
升级版的改革开放; 它不仅是古丝绸之路的伟大复兴, 也是外语人才的复兴之路, 因为它不仅为外语人才 提供巨大的就业市场, 而且将改变外语人才的专业结构和就业格局。然而, “一带一路” 建设不再需要以 英语为主要语种的单语种人才和只掌握语言工具无专业背景的纯语言型人才。语言背后专业技能的缺乏, 将削弱一个国家的跨文化交际能力、商业竞争能力, 威胁该国的国际地位、经济发展和非传统领域国家安 全 ${ }^{[4]}$ 。正如外语能力是一个国家改革开放的前提条件一样, 外语人才储备是 “一带一路” 建设的先导任务。 三十年前, 改革开放国策的确立掀起了全国外语人才培养的浪潮。三十年后, “一带一路” 建设国策的提 出必将掀起新一股外语人才培养的热潮。“一带一路” 国策提出后, 北外、上外、广外、西外等学校相继 开设了丝路建设所需的复合专业外语人才和小语种外语人才，纷纷为丝路建设储备合格的外语人才。

目前, 语言和道路不通是 “一带一路” 建设的主要障碍, 国家政府在规划施工中巴铁路，中尼铁路、 中吉乌铁路的同时, 西部地区各省也在未雨绸缪, 抢占先机。甘肃省已经开始着手为经济带建设制定 “以 人为本” 的外语人才培养方案。西安已列入新丝绸之路经济带的起点, 与洛阳、重庆并列入选中国丝绸之 路首批申遗名单，陕西省在人力资源和历史文化条件方面有着得天独厚的优势，必将担任起为经济带建设 培养外语人才的历史重任。陕西省西北大学成立了中亚学院和丝绸之路研究院, 西安外国语大学成立了中 亚学院, 旨在为丝路建设培养外交和经济领域的优秀外语人才。陕西省副省长庄长兴要求: 新成立的中亚 学院和丝绸之路研究院应充分发挥学科优势和专业特点, 选派高层次人才出国培训, 为逐步形成区域大合 作助力, 并通过外语人才的外宣不断增进互信、巩固友好、加强合作，与丝路沿线国家合作共赢、繁荣发 展。与此同时, “一带一路” 沿线国家纷纷成立孔子学院为亚、非、欧三洲培养经济合作与文化交流的外 语和外交人才。

“一带一路” 建设需要的是既有某一专业领域的精深知识又有良好外语表达能力的人才, 而不是纯语 言型人才。外语人才的专业技能应应用于国计民生, 应用于各个行业领域, 而不是只服务于学校和培训机 构 $^{[5]}$ 。因此西部地区在制定外语人才培养方案时, 应注意将当前的政治、经济和社会发展需要与长远的外 语事业协调一致。这就要求西部地区不能完全按照传统模式培养外语人才, 要改变在外语专业学习中忽视 自然科学和其他社会科学知识的观念, 要摒弃 “学好外语的最高境界就是忘掉母语” 的谬论, 因为如果把 母语都忘了, 如何把英语翻译成母语; 要彻底抛弃 “只要能说一口流利的英语, 就能走遍天下都不怕” 的 错误观点, 因为没有内容实质的口语就像县花一现, 只能看不实用; 要改变学习方式和手段陈旧老化的状 况; 要改变在外语技能训练中过分强调模仿记忆, 而忽视创新思维和能力培养的做法。教育部高教司发布 的《关于外语专业面向 21 世纪改革若干意见》指出: “市场对单纯语言文学专业毕业生的需求量正逐渐减 少, 外语专业必须从单科的 “经院式” 人才培养模式转向宽口径、应用性、复合型的培养模式。培养外语 与其他有关学科专业相结合的 “复合型” 人才, 使之服务于社会, 服务于 “一带一路” 建设, 是外语人才 可持续发展的出路。培养 “专业知识+外语技能+文化素养”一体化的复合应用型人才不仅是 “一带一路” 建设所需, 也是产业转型升级的必然趋势, 是科学技术发展的必然趋势, 是社会主义市场经济发展的必然 趋势, 它为西部地区外语人才发展指明了方向, 具有跨时代的战略意义。

\section{3 “一带一路”建设背景下西部地区外语人才可持续发展研究}

中国不仅西部地区的外语人才质量远远落后于西方发达国家, 就连广上北及沿海城市的外语人才质量 也滞后于西方发达国家，他们先进的国际化理念很值得我们学习和借鉴。经济高度发达的美国、德国、澳 
大利亚、日本都很重视其国民外语能力的培养, 而他们的外语人才培养不同于中国。总结起来, 西方发达 国家的外语人才培养模式与中国的外语人才培养模式主要有以下两点差异。第一，西方国家不以某种单一 的语言形式主宰外语学习, 学校通常开设可供选修的汉语、法语、西班牙语等多种语言, 所以在欧洲社会, 一个人会讲好几种语言是常有的现象，而中国的外语学习主要以英语为主，语种单一。第二，西方国家非 常重视外语与专业相结合的复合应用型外语人才的培养，所以国外很多在国家安全、生命科学、工业制造、 医学等领域的专门人才也具有高水平的外语能力, 而中国在改革开放以来的三十年里专注于培养纯语言型 人才。

\section{1 借鉴西方发达国家的先进理念和经验}

德国是世界近代高等教育的奠基者，其先进的外语教育理念对中国有很大的启示。德国的高校一般要 求学生在大学期间同时学习两门专业----一门主专业 (120 学分) 和一门第二专业 (60 学分)。例如, 在 柏林自由大学学生如果选择英语、汉语、法语等外语作为主专业, 可供他们选择作为第二专业的有哲学、 经济学、跨文化交际、法学、社会学、国际政治等人文学科类专业。反之, 如果学生是以其他非外语类专 业作为主专业的话, 那么外语就可以作为他们的第二专业来学习, 如在柏林洪堡大学以法语作为主专业 的学生可以选择生物、化学、地理、信息学、物理等作为第二专业。此外，德国高校为了适应国际化的需 求开设了许多以英语为媒介的国际类课程, 有些课程还与国外高校实行联合培养, 如柏林洪堡大学的法 学、农业、医学以及一些自然和人文学科都开设有这样的国际类课程。德国高校外语人才培养的目标是为 专业人才的国际化服务的, 外语已经成为帮助学生学好专业知识的工具之一, 并以此来提高学生的学术交 流能力, 而不是为外语等级考试服务。

美国高校外语人才培养坚持以国家利益为价值取向的发展经历了三个重要阶段: 第一阶段是上世纪 50 年代末至 70 年代。在这一阶段, 美国和前苏联争霸。为了满足国家外交和安全利益的需求, 美国高校培 养的外语人才以俄语人才为主, 兼顾亚、非、拉国家和地区的语言人才; 学习内容除了语言之外, 还包括 有关国家和地区的历史、政治和文化风俗等。第二阶段是上世纪 70 年代至 90 年代。在这一阶段，为了提 高美国经济的国际竞争力, 美国高校重视以日语、韩语和汉语为主的东亚国家语言的学习, 强调外语人才 培养促进国家经济贸易发展的价值, 将外语学习和商学院的课程紧密联系起来。第三阶段是上世纪 90 年 代至今。随着全球化的深入, 美国关注其国家安全、外交利益和经济发展在全球化时代所遭遇的新挑战, 更加强调高级复合型外语人才培养。其外语语种培养不仅包含了世界上很多国家的语言学习, 还涉及有关 国家政治、经济、文化、历史、社会等所有领域知识的学习。美国外语人才培养以国家利益为价值基础的 人才培养目标的确立和达成, 为二战后美国逐步发展成为世界第一强国做出了重大贡献 ${ }^{[6]}$ 。无论是前苏联 的解体、海湾战争还是 9.11 事件后美国政府主导的全球反恐战争, 都体现了高级复合型外语人才的巨大 贡献。

澳大利亚语言政策 “教父” 约瑟夫 - 罗比安科 1983 年开始制定澳大利亚第一部体现多元文化的《国 家语言政策》。他在过去近 30 年一直拥有这样一个共识: 为维持国家战略安全和国际竞争力必须全力推进 外语人才培养。世界发展的趋势是多级化, 不再是美国一家独大。必须同时与尽可能多的国家进行交往, 而不能仅仅依赖以美国为首的英语国家。在此政策下，澳政府一直在刻意推进不同语种的全面教育，此举 既确保了澳大利亚的国家安全，又促进了澳大利亚的经济全球化进程。 


\section{2 结合国内政策方针、“一带一路”需求研究西部地区外语人才的可持续发展道路}

研究了西方发达国家外语人才培养的经验之后，不难看出：我国西部地区外语人才的专业缺失和外语 语种的发展单一，不仅导致了纯外语人才就业难、社会适应性差、职场成就低的局面，而且影响了国际交 流合作的的深度和广度，延缓了西部大开发的速率，也必将阻碍 “一带一路” 建设的进程。面临困境，教 育部将 “复合型” 外语人才列为 21 世纪外语人才发展的战略目标。在教育部 2012 年进行普通高等院校本 科专业目录的调整中, 外国语言文学学科本科专业发生了很大变化。调整前, 外国语言文学学科有 36 个 本科专业; 调整后, 达到了 62 个本科专业, 增加了 24 个外语语种和两个与英语相关的专业, 翻译专业和 商务英语专业列入目录内基本专业。由此可以看出: 过去以训练学生听、说、读、写、译基础语言能力为 主要目标的外语专业已经发展成为外语类专业, 即以语言为载体工具、以专业内容为依托、以应用为目标 的外语类专业 ${ }^{[7]}$ 。小语种人才和复合应用型英语人才是 “一带一路” 建设所迫切需求的, 而纯语言型和英 语单一型人才将被社会淘汰。因此，在 “一带一路” 建设的战略方针下，西部地区的外语人才应该响应国 家建设所需, 经济社会发展所需, 努力提高自己实现自身外语语言的专业复合化, 技术应用化, 将自己打 造成为 “一带一路” 建设所需的复合型外语人才, 以促进西部大开发, 促进丝路建设 ${ }^{[8]}$ 。

“纯语言型” 外语人才早已与社会发展严重脱节，“一带一路”建设迫切需求 “复合语种型、复合专 业型、复合技术型” 外语人才。在新的国际和国内环境下, 西部地区的外语人才只有向 “复合语种型、复 合专业型、复合技术型” 方向发展, 才能走出 “失业率高、职场成就低, 薪资低” 的困境。“走复合型道 路” 才是西部地区复合型外语人才可持续发展的出路。培养 “专业知识+外语技能+文化素养”一体化的复 合应用型外语人才不仅是 “一带一路” 建设所需, 也是产业转型升级的必然趋势, 是科学技术发展的必然 趋势, 是社会主义市场经济发展的必然趋势, 它为西部地区外语人才发展指明了方向, 具有跨时代的战略 意义 ${ }^{[9]}$ 。一方面, 复合型外语人才利用其专业优势为丝路沿线国家的贸易合作、能源引进、技术管理、文 化旅游等做出贡献，加强丝路沿线国家的共赢互利。另一方面，复合型外语人才利用其语言优势，用国际 上普遍接受的方式, 向世界推介西部地区的经济社会发展状况, 外宣西部地区的文化历史、风土人情, 让 丝路各国认识和了解西部地区, 使西部地区更快地融入 “一带一路” 建设, 从而推动区域合作水平、促进 西部大开发，加快 “一带一路” 建设国际化进程，同时为中国营造良好的周边政治、国防和民族环境。

\section{4 结论}

总之，在西部地区培养外语与其他相关专业技术相结合的复合型外语人才，使之服务于国计民生，服 务于西部大开发, 服务于 “一带一路” 建设, 拓宽和加深中国改革开放的领域, 不仅推动西部地区经济社 会快速发展, 也是西部地区外语人才可持续发展的出路 ${ }^{[10]}$ 。

\section{5 致谢}

基金项目：本论文为陕西省教育厅基金项目的部分研究成果，陕西省教育厅基金项目的项目名称为： 新丝绸之路经济带建设背景下的陕西复合型外语人才培养研究（15JK1130）。

\section{Acknowledgement}

Fund Project: This paper is part of the research results of Shaanxi Province Education Department Fund Project. The title of Shaanxi Province Education department Fund Project is: Research on the Cultivation of Interdisciplinary Foreign Language talents in Shaanxi province 
under the background of The New Silk Road Economic Zone construction (15JK1130).

参考文献:

[1] Hutchinson T. \& Waters A. English f or Specific Purposes [M]. Shanghai: Shanghai Foreign Language Education Press, 2002.

[2] 曹德明. 高等外语院校国际化外语人才培养若干思考 [J]. 外语教学理论与实践, 2011, (3) :5.

[3] 戴炜栋. 关于面向 21 世纪培养复合型高级外语人才发展战略的几个问题 $[J]$. 外语界, 2010, (4):1-3.

[4] 胡壮麟, 对中国英语教育的若干思考 [J], 外语研究, 2002，（3）: 124-126。

[5] 束定芳. 外语教学改革：问题与对策 [M]. 上海:上海外语教育出版社, 2009.

[6] 周玉忠. 美国语言政策研究 [M]. 北京: 外语教学与研究出版社, 2011.

[7] 王守仁. 英语专业人才培养模式的改革与实践 [J]. 中国大学教学. 2012，(11)：136-137.

[8] 文秋芳. 英语专业创新人才培养体系的研究与实践 [J]. 国外外语教学, 2002, (4) :53-55.

[9] 赵蓉晖. 国家战略视角下的外语与外语政策 [M], 北京: 北京大学出版社, 2012.

[10］仲伟合. 英语类专业创新发展探索 [J].外语教学与研究，2014，(1)：128-123.

\section{References:}

[1] Hutchinson T. \& Waters A. English f or Specific Purposes [M]. Shanghai: Shanghai Foreign Language Education Press, 2002.

[2] Cao Deming. Thoughts on international foreign language talents training in higher foreign language colleges [J]. Foreign Language Teaching Theory and Practice, 2011, (3): 5.

[3] Dai Weidong. A series of questions on the development strategy of cultivating compound advanced foreign language talents in the 21 st century [J]. Foreign Language, 2010, (4): 1-3.

[4] Hu Zhuanglin. Some thoughts on Chinese English education [J], foreign language research, 2002, (3): 124-126.

[5] Bie Dingfang. Foreign Language Teaching Reform: Problems and Countermeasures [M]. Shanghai: Shanghai Foreign Language Education Press, 2009.

[6] Zhou Yuzhong. American language policy research [M]. Beijing: Foreign Language Teaching and Research Press, 2011.

[7] Wang Shouren. English professional talent training model reform and practice [J]. Chinese University Education. 2012, (11): 136-137.

[8] Wen Qiufang. Research and practice of English professional innovation talent training system [J]. Foreign Language Teaching, 2002, (4): 53-55.

[9] Zhao Ronghui. Foreign language and foreign language policy from the perspective of national strategy [M], Beijing: Peking University Press, 2012.

[10]Zhong Weihe. Research on the innovative development of English major. Foreign Language Teaching and Research, 2014, (1): 128-123. [J]. 